\title{
Accessibility of medical information by medical officers attached to divisional hospitals in rural Sri Lanka
}

\author{
M.P.P. Dilhani ${ }^{1}$, W. Senevirathne ${ }^{2}$, C. Abeysena $^{3}$
}

\begin{abstract}
Medical Officers (MOs) need to update their knowledge with diagnosis of diseases, current treatment modalities, guidelines on management etc. in order to provide a better service to the intended communities. The present study attempts to identify the information needs, perceived barriers and challenges of MOs attached to "Divisional Hospital Type-C" (DH Type-C) (rural) hospitals in Sri Lanka.This research was a descriptive study. A Self Administered Questionnaire was used as the data collection tool. The study population consists of MOs in DH Type-C Hospitals in Sri Lanka. Sample size was calculated using the Lwanga's and Lemeshow's formula. Accordingly, there were 400 MOs attached to the $192 \mathrm{DH}$ Type-C. Study shows that information about diagnosis, drug, treatment and patient data were identified as highly important by rural MOs. Data suggested that a higher proportion of aged MOs needed medical information than did young MOs. Also, it can be seen that the main driving purposes of MOs' information needs were to be up to date; answering patients' and their families' questions, and to answer colleagues' questions and confirm opinion. Internet, medical blogs, medical devices and personal contacts with colleagues were most highly used as sources of information. Further, most MOs suggested that if the medical authority could develop a proper medical system to help MOs to continue with health education, that will be a fruitful activity for the country.
\end{abstract}

Keywords: Medical Information Needs, Medical Information Sources, Medical Information Channels, Medical Information Barriers, Rural Hospitals, Sri Lanka, DH Type-C

1 Senior Assistant Librarian, Postgraduate Institute of Medicine, University of Colombo, Sri Lanka. Email: dilhani@pgim.cmb.ac.lk, (D) https://orcid.org/0000-0002-8351-6568

2 Former Librarian, Open University of Sri Lanka. Email: wathmanel.ousl@gmail.com

${ }^{3}$ Senior Professor, Faculty of Medicine, University of Kelaniya, Sri Lanka. Email: chrishantha-abeysena@kln.ac.lk 


\section{Introduction}

Medicine is a discipline where science and practice come together to address very crucial human requirement, that is health of the people. The science and practice of medicine address the diagnosis, prognosis, treatment and prevention of diseases. The medical information (MI), that is inclusive of all these categories expects to find answers for the queries posed by the healthcare professionals including Medical officers (MOs) and by the patients. Thus the MI is a specific category of information where medical, pharmaceutical and medical administration consist of considerable number of the queries. In this regard queries posed by health care officers carry paramount importance, therefore MOs need to update their knowledge in diagnosis of diseases for current treatment modalities, guidelines on management etc. in order to provide a better service to the intended communities. MO is a prominenet figure in medical services and plays an active role in implementing medical care of patients.

Accessing new information in an up-to-date manner is essential for the evidence-based clinical decision-making (Bates et al., 2001; Friedman et al., 2001). If information needs remain unanswered at the time of making medical related decisions, the practitioner may not be able to perform the task in an authentic manner. Consequently, there may be medical errors such as incorrect diagnosis, error in administering treatment or failure to provide prophylactic treatment,(Kohn et al., 2008) which impacts over the quality of treatment and outcomes in medical care (Haynes et al., 1990).

The literature supports that MOs who serve in the rural hospital setting in certain countries are apparently in disadvantageous position in obtaining medical information required for their continued professional education (Amararachchi et al., 2014; Curren et al., 2006). It was observed through many known channels that there is no proper information system for MOs who work in the rural areas of Sri Lanka to access formal medical information to fulfill their information requirements. This study has been conducted to explore the accessibility and barriers relating to utilization of information by the MOs working in the Divisional hospitals Type-C in Sri Lanka. 


\section{Research Objectives}

MOs who provide health services to rural communities require a range of high-quality medical information to serve rural communities and for their own professional and educational development. If their needs are not analyzed in depth, it will directly affect patient care. Therefore, it is important to help them to acquire the most relevant health-related information when needed. The provider of information services should design services for the medical profession to assist MOs in providing better service to the communities they serve. However, due to lack of understanding of information needs, it is difficult to know whether such services satisfy the MOs' information needs. A better understanding of information needs could lead to better assessment of these information requirements. Proper investigation of information needs might put the information provider at a better place to design, develop and implement appropriate information systems that respond to the MOs' information needs in rural areas. It is evident that poor accessibility to medical information has a direct impact on the medical officers who provide treatment in rural hospitals (Dolea, 2009).

The main objective of this study is to explore the accessibility of medical information of the medical officers attached to rural (DH Type-C) hospitals in Sri Lanka..

To achieve the main objectives, following four specific objectives were drawn:

i. To describe the accessibility of MI by the MOs attached to rural (DH Type-C) hospitals in Sri Lanka

ii. To describe MI sources utilized by MOs attached to rural (DH Type-C) hospitals in Sri Lanka

iii. To explore MI channels utilized by MOs attached to rural (DH Type-C) hospitals in Sri Lanka

iv. To describe determinants (characteristics) of MI channels utilized by MOs attached to rural (DH Type-C) hospitals in Sri Lanka 


\section{Literature Review}

This study focuses on the following three models particularly, Leckie et al. (1996) general model of the Information-Seeking of Professionals, Shaughnessy et al. (1994) for doctors' information needs model and Can Meds Framework formulated by Royal college of Physicians in Canada (1996) cited by Dilhani.,(2017). It is observed that the majority of medical experts are employed in the urban areas, but majority of the population still lives in rural and remote areas (WHO, 2016). Dolea (2009) stated that "with the present inequity of distribution of medical officers and specialists in Sri Lanka it is difficult to mention that there is an impartial health service except in the case of the public health services." This clearly visible imbalance in the distribution of MOs in the country and low level of medical facilities provided to rural and remote medical centers that serve the majority of the population tend to place the rural citizen at a high level of health risk. According to health statistics (Ministry of Health, 2017), 72.7\% of medical specialists serve in urban centers, $25.1 \%$ in semi-urban areas and only $2.2 \%$ serve in rural areas.

According to MOH Sri Lanka (2016), 80\% of its main healthcare centers are located in cities. Therefore, rural communities are at a greater disadvantage in receiving healthcare services. According to the findings of the survey done by Amararachchi et al., (2012), due to geographical and infrastructure, based barriers, the rural medical officers are at a disadvantage when compared to the urban medical officers in Sri Lanka and they do not have access to information and have unmet needs on clinical problems and day to day medical practice. Health statistics have revealed that there is a scarcity of specialist doctors serve in the rural and remote areas (MOH, 2016).

Several significant studies examine the information needs of rural and nonrural MOs by exploring sources of medical information (PakenhamWalsh, 2009; Davies, 2007; Grefsheim et al., 2007; Bryant, 2004); Gorman, 2001). Research on the use of technology by MOs include studies on computer use, end user searching, and healthcare information system. (Andualem et al., 2013; Dimond et al., 2016; Eysenbach, 2002; Dorsch et al., 1997; Crandall et al., 1994; Bowden et al., 1994). Several barriers are consistently apparent from the reviewed studies covering the period of 1990 to 2017: lack of time, isolation, lack of library services, technology illiteracy, 
lack of equipment, demands of a strenuous practice. Although many of these barriers are shared by urban health professionals, these appear to be more prominent among rural health professionals. (Andualem et al., 2013; Gatero, 2010; Curran et al., 2006; Janes et al., 2005; D'Alessandro et al., 1998; Smith, 1996; Shelstad \& Clevenger, 1996; Bowden et al., 1994; Lundeen, 1994; Dee \& Blazek, 1993).

\section{Methodology}

Study population was MOs, those attached to 289 DH Type-C in Sri Lanka (MOH, 2016). Cluster sampling method was used and a Divisional Type-C hospital was considered as a cluster and, unit of analysis is the MOs attached to each Divisional Type-C hospitals. The number of MOs selected from each Regional Directors Health Services (RDHS) area is proportionate to the number of Divisional Type-C hospitals in that RDHS area. It is expected that two medical officers are attached to each hospital. Therefore, to achieve the required sample size from each RDHS area, study clusters were selected randomly. Considirng the anticipated percentage of 50\% for multiple variables assessed, precison of 5\% and confidence interval of $95 \%$, according to the calculations, using the Lwanga and Lemeshow, 1991 formula, a minmum sample size of 384 MOs were required for this study, 400 MOs were included in the study, using two staged cluster sampling technique. A self administered questionnaire was developed to obtain the answers for the research questions of the study. Part one covered demographic data, including respondent's name (optional), gender, age, and health facility related questions. Part two covered questions relating to need of clinical information. Questions regarding clinical information sources were covered in part three. Descriptive statistics was used to analyze the data which include: frequency distribution, percentages and standard deviations. A five point Likert scale was also used in questionnaire to obtain the opinions on different aspects covered in the research questions.

Ethical approval for this study was obtained from the Faculty of Graduate Studies, University of Colombo. Permission for accessing Divisional Hospital Type-C, obtained from the Ministry of Health Sri Lanka to collect data from MOs. 


\section{Results and Discussion}

Of the 400 respondents, $61.8 \%$ were male MOs and $38.3 \%$ were female. Respondents age was broad; with 251(62.8\%) between the age group of 26 to 40 years, $100(25 \%)$ between $41-50$ years, 47 (11.8\%) between 51-60 years, and $2(0.5 \%)$ between 61 and above . Responses regarding the courses followed were; certificate courses $4.5 \%$, Postgraduate Diploma 5\%, MSc $1 \%$, Others $1 \%$ and None $89.3 \%$ respectively. To check, how busy MOs attached to DH Type-C were, they were asked to indicate the average number of patients they managed to see per day. The results showed that the majority of rural MOs (247 or 61.8\%) managed to see more than 75 patients a day; 98 (24.5\%) of the rural doctors indicated that they managed between 50 and 75 patients per day; and $55(13.8 \%)$ indicated less than 50 daily consultations. The respondents were asked about their working experience in DH Type-C hospitals. Majority of the respondents had 6-10 years of experiences working in DH Type-C hospitals.

\section{Purpose of using MI by MOs}

It can be seen from Figure 1, that information need of MOs is to be up to date, for patient care, for medical education, to answer colleagues' questions, to answer patients' and their family's questions, and to write research papers. It is almost certain that the main purpose of using different kinds of information is to provide patient care and to be up to date. Furthermore, the most common kind of information that the large proportion of MOs needed in patient care was general information about diagnosis, patient data, drug, diet and nutrition, new medical guidelines, new medical equipment, medico legal information, and medical statistics. However, from the table it can be estimated that apart from patient care and being up to date not all kinds of information are equally used for all purposes. For instance, patient data are more heavily used to answer patient and their families'questions than other kinds of information. Diagnosis information (96.3\%) is more likely to be for education purposes than other kinds of information. MOs hardly used medical information to write journals articles $(0.8 \%)$. This might be due to lack of time. However, information need was therefore perceived as problem-oriented. 


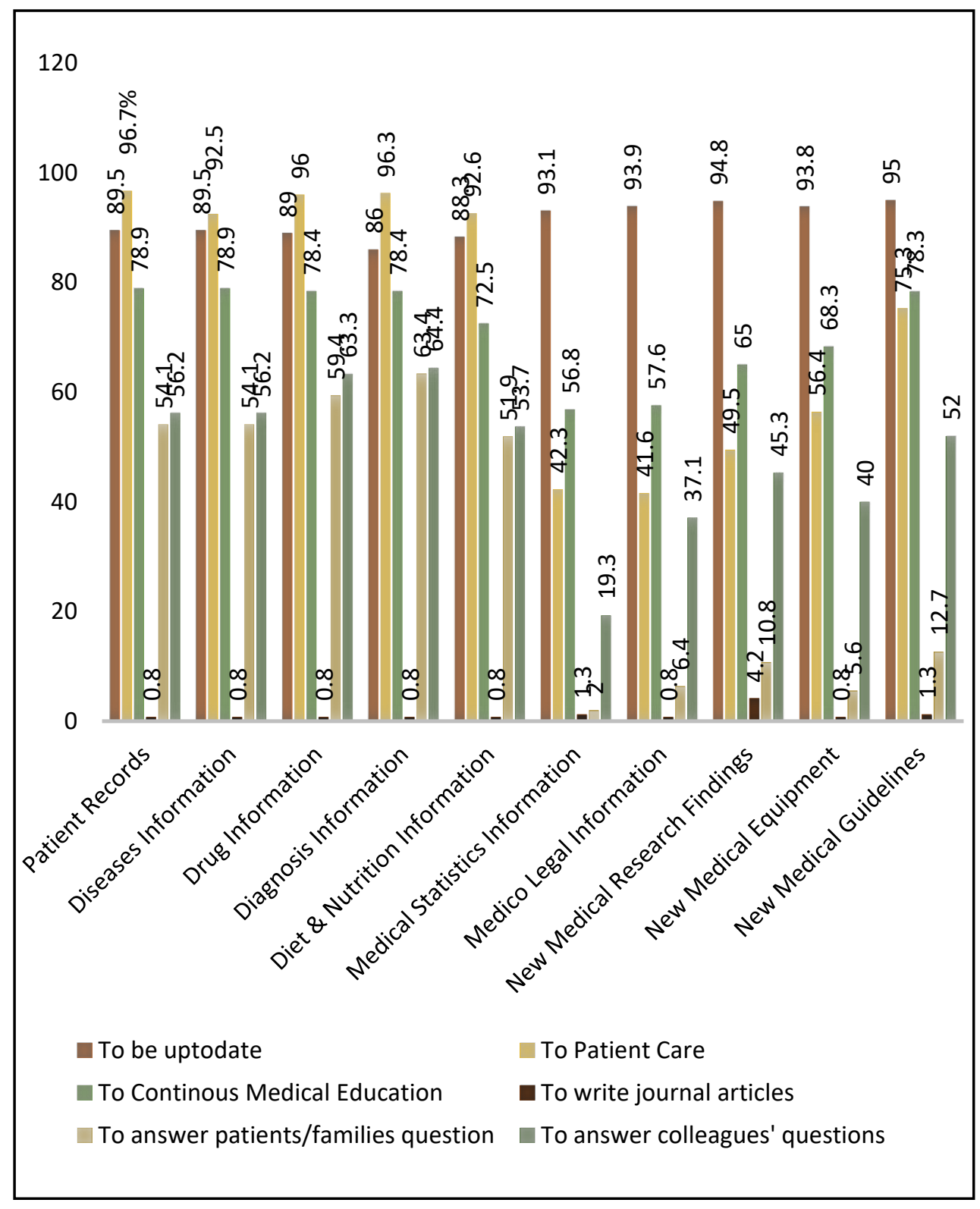

Figure 1. Purpose of using information by rural Medical Officers

\section{Sources of Medical Information}

Overall the top sources of information used by rural MOs were: books $94.3 \%$, and professional newsletters and government publications $85 \%$, journals $39.1 \%$, Confrence Papers 18.8\%, Technical Reports $14.3 \%$ and 
Drug Company Presentations 13.3\%. Although the use of electronic sources to fulfill information needs is becoming omnipresent, MOs rely much more heavily on books compared to the other electronic sources. The results of the use of MI sources are presented in Figure 2.

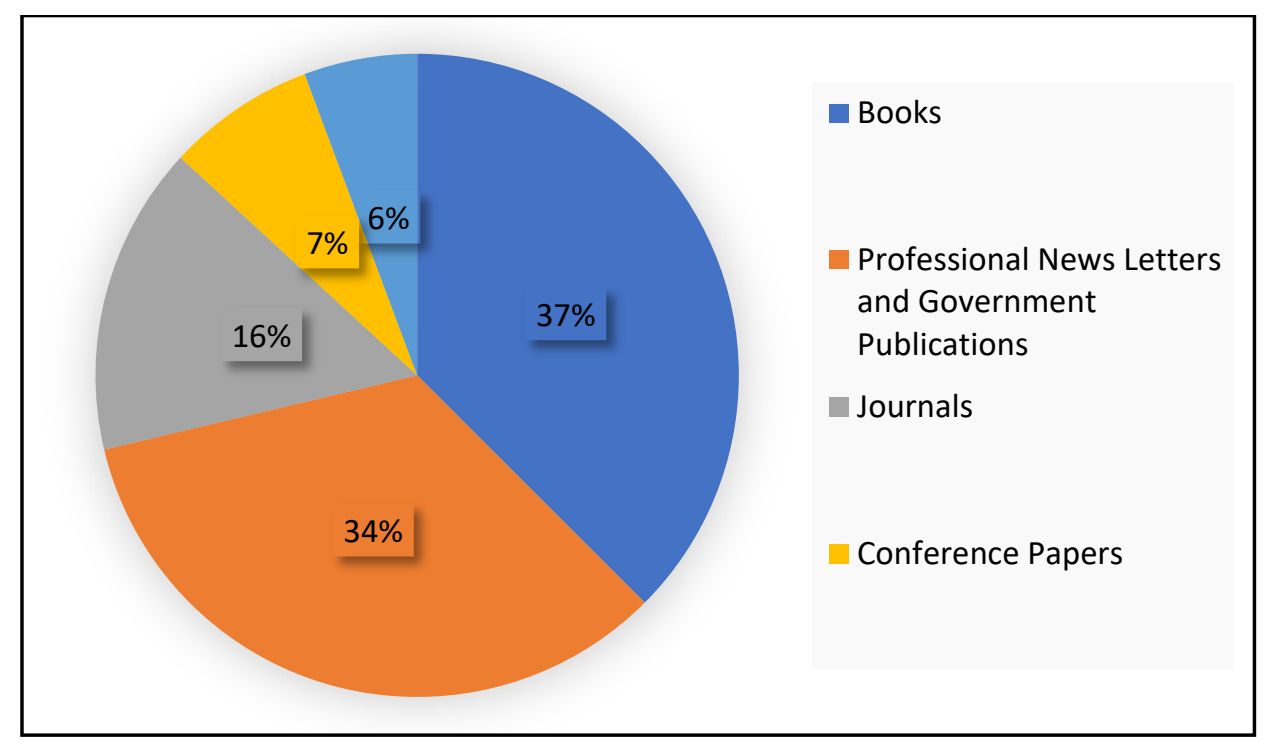

Figure 2. Use of Medical Information Sources

Medical Information Channel utilized by MOs attached to DH Type-C in Sri Lanka

According to the results, MOs were meeting some portion of their information needs through a diversity of channels. The first information channel that was used by MOs to access information was the Internet (312 MOs 78.1\%), then colleagues, specialists and consultants (199 MOs 49.8\%), followed by the Medical blogs (198 MOs 49.5\%), then Professinal Meetings (79 MOs19.8\%) and finally the medical faculty library (15 MOs 3.8\%). Although hospital libraries and a medical faculty library are not used as frequently as the internet and personal contacts, $45.5 \%$ of MOs indicated that they are satisfied with the information obtained from the professional meetings and $34.8 \%$ are satisfied with the information services of the medical blogs. 
Table 1. Medical Information Channels utilized by MOs attached to DH Type-C in Sri Lanka

\begin{tabular}{|c|c|c|c|c|c|}
\hline $\begin{array}{l}\text { Determinants } \\
\text { MI Channels }\end{array}$ & 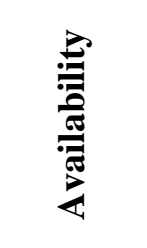 & 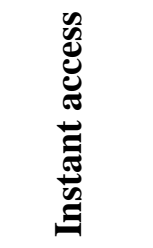 & : & 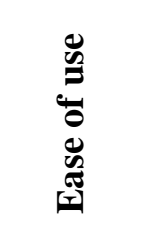 & 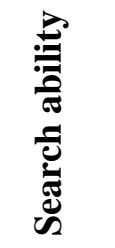 \\
\hline $\begin{array}{l}\text { 1. Hospital Libraries and } \\
\text { other Medical } \\
\text { Libraries }\end{array}$ & $\begin{array}{r}163 \\
(40.8 \%)\end{array}$ & $\begin{array}{r}72 \\
(18 \%)\end{array}$ & $\begin{array}{r}104 \\
(26 \%)\end{array}$ & $\begin{array}{r}42 \\
(10.5 \%)\end{array}$ & $\begin{array}{r}19 \\
(4.8 \%)\end{array}$ \\
\hline 2. Internet & $\begin{array}{r}204 \\
(51 \%)\end{array}$ & $\begin{array}{r}94 \\
(23.5 \%)\end{array}$ & $\begin{array}{r}92 \\
(23 \%)\end{array}$ & $\begin{array}{r}7 \\
(1.8 \%)\end{array}$ & $\begin{array}{r}3 \\
(0.8 \%)\end{array}$ \\
\hline $\begin{array}{l}\text { 3. Colleagues, specialists } \\
\text { and consultants in the } \\
\text { hospitals }\end{array}$ & $\begin{array}{r}225 \\
(56.3 \%)\end{array}$ & $\begin{array}{r}85 \\
(21.3 \%)\end{array}$ & $\begin{array}{r}78 \\
(19.5 \%)\end{array}$ & $\begin{array}{r}6 \\
(1.5 \%)\end{array}$ & $\begin{array}{r}6 \\
(1.5 \%)\end{array}$ \\
\hline 4. Professional Meetings & $\begin{array}{r}232 \\
(58 \%)\end{array}$ & $\begin{array}{r}85 \\
(21.3 \%)\end{array}$ & $\begin{array}{r}74 \\
(18.5 \%)\end{array}$ & $\begin{array}{r}2 \\
(0.5 \%)\end{array}$ & $\begin{array}{r}7 \\
(1.8 \%)\end{array}$ \\
\hline $\begin{array}{l}\text { 5. Hospital Information } \\
\text { System }\end{array}$ & $\begin{array}{r}234 \\
(58.5 \%)\end{array}$ & $\begin{array}{r}85 \\
(21.3 \%)\end{array}$ & $\begin{array}{r}75 \\
(18.8 \%)\end{array}$ & $\begin{array}{r}5 \\
(1.3 \%)\end{array}$ & $\begin{array}{r}1 \\
(0.3 \%)\end{array}$ \\
\hline 6. Mobile Devices & $\begin{array}{r}236 \\
(59 \%)\end{array}$ & $\begin{array}{r}88 \\
(22 \%)\end{array}$ & $\begin{array}{r}68 \\
(17 \%)\end{array}$ & $\begin{array}{r}6 \\
(1.5 \%)\end{array}$ & $\begin{array}{r}2 \\
(0.5 \%)\end{array}$ \\
\hline 7. Medical Blogs & $\begin{array}{r}171 \\
(42.8 \%)\end{array}$ & $\begin{array}{r}85 \\
(21.3 \%)\end{array}$ & $\begin{array}{r}134 \\
(33.5 \%)\end{array}$ & $\begin{array}{r}6 \\
(1.5 \%)\end{array}$ & $\begin{array}{r}4 \\
(1 \%)\end{array}$ \\
\hline
\end{tabular}

Source: Survey data

MOs need to continually update their skills and knowledge, through processes of continuous learning and improvement. After the university, meetings of local medical associations' congresses or postgraduate courses would be lifelong learning avanues. Most of the respondents interviewed attended local and international meetings to exchange ideas with colleagues, to take educational courses to stay up-to-date on current medical practices. Although it is not a primary source of answers to the specific patient care questions, medical meetings serve as a valuable source of general medical information. Attending to these would be important as it would help ensure that they can deliver high quality levels of Healthcare.

Identification of barriers and obstacles

Data shown in Table 2 identifies a number of barriers to accessing MI for MOs who serve the rural community in Sri Lanka. 
Table 2. Problems encountered by MOs when searching medical information

\begin{tabular}{lrr}
\multicolumn{1}{c}{ Medical Information Barriers } & \multicolumn{2}{c}{ Currently faced } \\
& \multicolumn{1}{c}{ Yes } & \multicolumn{1}{c}{ No } \\
\hline 1. Lack of access to a medical faculty & $346(86.5 \%)$ & $54(13.5 \%)$ \\
$\quad$ library or academic health sciences library & & \\
2. Lack of time for reading & $168(42 \%)$ & $232(58 \%)$ \\
3. Lack of local information & $316(79 \%)$ & $84(21 \%)$ \\
4. Lack of awareness of available information & $255(63.8 \%)$ & $145(36.3 \%)$ \\
5. Geographic Isolation & $345(86.3 \%)$ & $55(13.8 \%)$ \\
6. Distance from specialist colleagues & $369(92.3 \%)$ & $31(7.8 \%)$ \\
7. Inadequate road and telecommunication & $223(55.8 \%)$ & $177(44.3 \%$ \\
$\quad$ infrastructure & & \\
8. Lack of computer literacy & $64(16 \%)$ & $336(84 \%)$ \\
9. Lack of technological equipment & $120(30 \%)$ & $280(70 \%)$ \\
10. Cost for subscription for databases/articles & $336(84 \%)$ & $64(16 \%)$ \\
11. Low opportunities for clinical practice & $236(59 \%)$ & $164(41 \%)$ \\
12. Unreliability of the information in the & $247(61.8 \%)$ & $153(38.3 \%)$ \\
$\quad$ internet & & \\
13. Software problems & $311(77.8 \%)$ & $89(22.3 \%)$ \\
14. Non availability of health information & $400(100 \%)$ & \\
$\quad$ system & & \\
15. Non avalibility of Medical consultants in the & $400(100 \%)$ & \\
$\quad$ hospital & & \\
16. Irregular working hours of hospital & $346(86.5 \%)$ & $54(13.5 \%)$ \\
\hline Sour Survey data & &
\end{tabular}

Source: Survey data

All respondents agreed that nonavailability of a health information system and the nonavailability of medical consultants in the hospitals had direct impact on clinical decision making process and their administrative aspects. Distance from specialist colleagues was the major barrier reported by majority (92.3\%) of respondents. Due to heavy workload and unavailability of medical information, irregular working hours of hospital was also a barrier reported by a large number (86.5\%) of respondents. Lack of local information and lack of awareness of available information resources were the most common problems. Geographic isolation (86.3\%); distance from specialist colleagues (92.3\%); lack of access to a medical library or academic health sciences library $(86.5 \%)$; inadequate road and telecommunications infrastructures (55.8\%); lack of local information (79\%); lack of awareness of available information (63.8\%); Unreliability of the information on the 
internet (61.8\%), and less opportunities for clinical practice (59\%) appeared to be other significant barriers for rural MOs. Nonavailability of library facilities in DH Type-C hospitals can be considered as another barrier.

The results of the present study show that MOs acquire information from different information sources for fulfillment of information needs. Due to scarcity of medical libraries in the hospitals, accessibility to books and journals is poor. MOs used books to be up to date and to confirm opinions $32 \%$, for patient care $42.8 \%$, education purposes $15.8 \%$, to answer patient/ families question $6 \%$, to answer colleague questions $22.3 \%$, to write journal articles 3.5\%. Government publications/Professional newsletters were used to be up to date, $41.8 \%$ and to confirm the opinions $19.3 \%$, for patient care $16.8 \%$, education purposes $37.5 \%$, to answer patient/ families question $4.5 \%$, to answer colleague question $41.3 \%$ and to write journal articles $1.8 \%$. The results of this study demonstrate how MOs use information sources to obtain the information they need. Respondents who had more years of working experience were more likely to need information because of their involvement in the work of colleagues or with junior MOs. On the other hand, rural MOs indicated that information about patient records was the most important information they needed.

Some associated issues were investigated regarding information resources, including: reasons for seeking the information, frequency, the place where they most frequently visited for information, how they keep and update the resources used and the problems they encountered in using the information resources. These included human sources, print sources, electronic sources, lectures, and drug company presentations. Human sources included colleagues, specialists and consultants in the hospital; visiting doctors; company representatives; and external experts. Print sources included books, journals, conferences, and research papers. The study identified factors that were believed to influence MOs' information source usage. Responses received confirms that a larger proportion of rural MOs (345 or 86.3\%) believed that it was easy to find what they needed from colleagues, specialists and consultants in the hospitals. 
According to observations, rural MOs in Sri Lanka are apparently in a disadvantageous position in; obtaining medical/health information for their clinical practice, patient care and professional upgrading. Due to professional, geographical isolation they are not certain as to where to go for the medical information they need. From a theoretical perspective, although radically new factors that affect information behavior have not been discovered, this research serves to support previous literature (Amararachchi et al., 2014; Andualem et al., 2013; Gatero, 2010; Pakenham-Walsh, 2009) provides depth, and comprehensively integrates the broad range of factors in relation to the medical population, which has not been done before. In rural Sri Lanka there is no proper channel for MOs to access formal information services to obtain the information they need. However, MOs were confronted with a wide range of barriers that influenced their use of different channels, as well as, their usage of different information sources due to unavailability of peer reviewed medical journal for rural community which address the rural special issues (ex. Snake bites, Self-poisoning patients, Cronical kidney disease, water contact diseases, Rabies) and unavailability of hospital libraries, unavailability of health information system, unavailability of proper system for continuous professional develoment programmes for rural MOs.

\section{Conclusions}

MOs who practice in DH Type-C in Sri Lanka have different information needs due to the very different environments within which they practice. The findings of this study will lead to address the issues of the areas in which information is lacking and would help improve the situation for maximizing the use of pooled information. To sum up, it appears that MOs' information needs are higher in the context of clinical and educational work, within which they are supposed to achieve particular tasks, such as decisionmaking, managing patient's health problems, teaching, or studying. In the course of accomplishing their tasks, MOs are encountered with patients with different health problems. Some of the health problems are clear and easily managed; however, others are less clear and led MOs to be anxious. They might think that they are aware of what to do and what results they are seeking for, but might not be sure of the impact of their intervention. With regard to ambiguity, it was that MOs lacked clarity; for example, if they 
were not satisfied with their understanding of the problem and what was involved in resolving the problem or when they were not sure of the final result that they were seeking for. Such a psychological state had implications on their knowledge state.

Data showed that MOs needed different types of information in order to manage their knowledge state, which in its turn, may help complete the task. The different types of information were clustered under three main categories: patient data, general health information, and managerial information. Thus, to acquire such information MOs searched for information either themselves or through a mediator. Information searching involved different types of information sources, which may be human, paper or electronic sources; through different channels, which may be personal, hospital, university, medical organization libraries or through the internet.

The study highlights the importance of access to information resources in hospital settings. While accessibility of MI is critical in delivery of quality health care services, there are many problems that are inherent in attempting to meet the information needs of MOs at in DH Type-C in Sri Lanka. This research has addressed a number of questions related to information needs and helps us better understand current information environment at DH TypeC. However results of the study points out;, MOs encountered different types of barriers that affected their access to information when trying to fulfill their needs. The different barriers were associated with personal issues, such as lack of self-sufficiency, and paper or electronics-related issues such as unavailability and poor accessibility. With more reliable data on medical information needs, it will be possible to conduct prospective studies on the clinical benefit of providing MOs with decision support tools that meet those needs.

\section{Recommendations}

According to the overall findings of the study, it was obvious that there is a need for a big shift in building and improving the system for providing health information in Sri Lankan rural hospitals. Although change is likely to take time, it is clearly vital that a much-needed health information management service should be supported by high-quality resources and advanced technologies. To ensure this, some recommended strategies and 
practical solutions are proposed. Establish and implement a clear strategy and plan showing the flow of information provision in rural and other related healthcare delivery systems including the information system infrastructure. Also implementing effective information management system with orientation and training programmes for MOs. Improve the communication process and provide ICT resources such as a paging system, mobile phones, high-quality and speedy telephone services, faxing, and email services along with fast access to the Internet to help MOs in their information communication process. Improve the current awareness of the availability of information services in the hospital by providing posters in hospitals, organizing orientation seminars and tour programmes for new staff MOs to introduce them to the different information services available in their hospitals. Improve accessibility to online resources in all units and sub- units in the hospitals allowing MOs to access information at any time from any place they need it. Training MOs by Medical librarians will build confidence and positive attitudes in using and interacting with different systems of information provision, however, training should be extensive, well structured and formally scheduled. Some examples of training are search strategy techniques, online and electronic resources and search for information to ensure good practice. Also, training is needed to improve communication skills and time-management.

\section{Further research}

Following recommendations are made based on the conclusions of the study in order to meet the information needs of the primary care MOs working in remote government health facilities. Primary care MOs should be provided with assistance of senior doctors/consultants, so that they may discuss the management and treatment choices of a difficult clinical case with seniors. This step will avoid huge numbers of referral cases to tertiary and urban hospitals and also improve patient treatment process. At least a small library in each hospital is essential. Latest editions of textbooks, handbooks, atlases, drug guidelines and encyclopedias should be made available in these government health facilities. Likewise, small libraries in the premises of health facilities should be developed. This step will encourage MOs to learn new techniques and methods. 


\section{References}

Al-Dousari, E. (2009). Information needs and information seeking behaviour of doctors in kuwait government hospitals: an exploratory study. PQDT - UK \& Ireland, https://hdl.handle.net/2134/9786

Ali Salem Khalil Mohamed Arraid. (2011). Information needs and information seeking behaviour of Libyan doctors working in Libyan hospitals. Loughborough University's Institutional Repository, 350. https://core.ac.uk/reader/2744670

Amararachchi, J. L., Perera, C., \& Pulasinghe, K. (2012). Achieving Quality Healthcare through Knowledge Management Initiatives in Health Institutions in Rural and Remote Areas in Sri Lanka. The First National Conference on Technology \& Management.

Amararachchi, J. L., Perera, C., \& Pulasinghe, K. (2014). Towards Knowledge Management for Healthcare: Effects of Latest Medical Information for the Quality of Healthcare in the Developing Countries: A Case Study. Journal of Biomedical Engineering and Medical Imaging, 1, 117. https://doi.org/10.14738/jbemi.12.98

Andualem, M., Kebede, G., \& Kumie, A. (2013). Information needs and seeking behaviour among health professionals working at public hospital and health centres in Bahir Dar, Ethiopia. BMC Health Services Research, 13, 534 .

Bates, D. W., Cohen, M., Leape, L. L., Overhage, J.M., Shabot, M.M., \& Sheridan, T., (2001). Reducing the Frequency of Errors in Medicine Using Information Technology, Journal of the American Medical Informatics Association, 8(4), 299-308. https://doi.org/10.1136/jamia.2001.0080299

Bowden , V. M., Kromer, M. E., \& Tobia, R. C. (1994). Assessment of physicians' information needs in five Texas counties. Bulletin of the Medical Library Association, 82(2), 189-196. 
Bryant, S. L. (2004). The information needs and information seeking behaviour of family doctors. Health Information \& Libraries Journal, 21(2), 84-93. https://doi.org/10.1111/j.1471-1842.2004.00490.x

Curran, V. R., Fleet, L., \& Kirby, F. (2006). Factors influencing rural health care professionals' access to continuing professional education. Australian Journal of Rural Health, 14(2), 51-55. https://doi.org/10.1111/j.14401584.2006.00763.x

D'Alessandro, D. M., D'Alessandro, M. P., Galvin, J. R., Kash, J. B., Wakefield, D. S., \& Erkonen, W. E. (1998). Barriers to rural physician use of a digital health sciences library. Bulletin of the Medical Library Association, 86(4), 583-593.

Davies, K. (2007). The information-seeking behaviour of doctors: A review of the evidence. Health Information and Libraries Journal, 24(2), 78-94. https://doi.org/10.1111/j.1471-1842.2007.00713.x

Dee, C., \& Blazek, R. (1993). Information needs of the rural physician: A descriptive study. Bulletin of the Medical Library Association, 81(3), 259264.

Dilhani, M. P. ., Senevirathe, W., \& Abeysena, C. (2017). Information Needs and Seeking Behavior of Medical Officers Attached to Rural Hospitals ( D H Type - C ) in Sri Lanka. 4th Annual Research Symposium on Social Sciences and Humanities, National Centre for Advanced Studies in Humanities \& Social Sciences (NCAS), 221-224.

Dimond, R., Bullock, A., Lovatt, J., \& Stacey, M. (2016). Mobile learning devices in the workplace: 'as much a part of the junior doctors' kit as a stethoscope' BMC Medical Education, 16. https://doi.org/10.1186/s12909016-0732-z

Dolea, C. (2009). Increasing access to health workers in remote and rural areas through improved retention. World Health Organization, (February), 2-4. 
Eysenbach, G., \& Wyatt, J. (2002). Using the Internet for surveys and health research. Journal of Medical Internet Research, 4(2), 76-94. https://doi.org/10.2196/jmir.4.2.e13

Friedman, C., Gatti, G., Elstein, A., Franz, T., Murphy, G. \& Wolf, F. (2001). Are clinicians correct when they believe they are correct? Implications for medical decision support. Studies in health technology and informatics. 84. 454-8. https://doi.org/10.3233/978-1-60750-928-8-454

Gatero, G. (2011). Utilization of ICTs for Accessing Health Information by Medical Professionals in Kenya: A Case Study of Kenyatta National Hospital. Journal of Health Informatics in Developing Countries, 5(1), 6088. Retrieved from http://www.jhidc.org/index.php/jhidc/article/view/55

Gorman, P. (2001). Information needs in primary care: A survey of rural and nonrural primary care physicians. Studies in Health Technology and Informatics, 84, 338-342. https://doi.org/10.3233/978-1-60750-928-8-338

Grefsheim, S. F., \& Rankin, J. A. (2007). Information needs and information seeking in a biomedical research setting: A study of scientists and science administrators. Journal of the Medical Library Association, 95(4), 426-434. https://doi.org/10.3163/1536-5050.95.4.426

Haynes, R. B., McKibbon, K. A., Walker, C. J., Ryan, N., Fitzgerald, D., \& Ramsden, M. F. (1990). Online Access to MEDLINE in Clinical Settings: A Study of Use and Usefulness. Annals of Internal Medicine, 112(1), 78-84. https://doi.org/10.7326/0003-4819-112-1-78

Kohn, L. T., Corrigan, J., Donaldson, M. S., McKay, T., \& Pike, K. (1999). To err is human. National Academy Press, (November).

Kohn, L. T., Corrigan, J. M., \& Molla, S. (2008). Rapporteur's Report Session I: Origin of the problem: Malcolm Ross. Regulatory Toxicology and Pharmacology (Vol. 52). https://doi.org/10.1016/j.yrtph.2007.09.017 
Lundeen, G. W., Tenopir, C., \& Wermager, P. (1994). Information needs of rural health care practitioners in Hawaii. Bulletin of the Medical Library Association, 82(2), 197-205.

Ministry of Health. (2017). Reorganising Primary Health Care in Sri Lanka preserving our progress, preparing our future Ministry of Health, Nutrition and Indigenous Medicine Sri Lanka. Ministry of Health,Nutrition and Indigenous Medicine. Retrieved from http://www.health.gov.lk

Ministry of Health. (2016). Policy Repository Of Ministry of Health. Ministry of Health, Nutrition and Indigenous Medicine of Sri Lanka, 226235.

Pakenham-Walsh, N., \& Bukachi, F. (2009). Information needs of health care workers in developing countries: A literature review with a focus on Africa. Human Resources for Health, 7, 1-13. https://doi.org/10.1186/14784491-7-30

Shaughnessy, A., Slawson, D., \& Bennett, J. (1994). Becoming an information master: a guidebook to the medical information jungle.le. J Fam Pract., 39(5), 489-499.

Shelstad, K., \& Clevenger, F. (1996). Information retrieval patterns and needs among practicing general surgeons: a statewide experience. Bull Med Libr Assoc, 84(4), 490-497.

Smith, R. (1996). What clinical information do doctors need? BMJ, 313(7064), 1062-1068. https://doi.org/10.1136/bmj.313.7064.1062

WHO. (2016). Barriers and Facilitating Factors in Access to Health Services in the Republic of Moldova. World Health Organisation Library, 9(9), 119163. 